\title{
COMPARING THE EFFECTIVENESS OF TWO READING INTERVENTION PROGRAMS FOR CHILDREN WITH READING DISABILITIES ${ }^{1}$
}

\author{
Comparación de la eficacia de dos programas de intervención \\ lectora para niños con dificultades en lectura \\ J.P. DAS - Denyse V. HaYward - George K. GeOrgiou \\ University of Alberta \\ Troy JANZEN \\ Taylor University College \\ Neelam BoorA \\ Nipisihkopahk Middle School
}

\section{Abstract}

The effectiveness of two reading intervention programs (phonics-based and inductive learning) was investigated with 63 First Nations children identified as poor readers in Grades 3 and 4 in Study 1, whereas in Study 2, the efficacy of booster sessions for inductive learning or PREP (PASS Reading Enhancement Program) was examined. The major dependent variables in Study 1 were pretest to posttest changes following intervention on reading tests for word reading and word decoding. Other dependent variables comprised tests of phonological awareness, rapid naming speed, and cognitive tests of Planning, Attention, Successive, and Simultaneous processing (PASS). Results of Study 1 showed a significant improvement on both reading tasks following inductive learning intervention, among children below the median in comparison with those above the median. The phonics-based program resulted in similar improvement in only one of the reading tasks, word decoding. Results are discussed in terms of approaches to reading intervention for children with persistent reading difficulties. In Study 2, the important dependent variables were word reading and word decoding, as well as passage comprehension. Results showed that PREP participants evidenced continued improvements in their reading skills, notably in comprehension.

Keywords: Phonics-based, Inductive learning, Reading, Remediation.

1. The research was supported by a grant from Social Sciences \& Humanities Research Council of Canada (SSHRC) to J. P. Das, principal investigator.

Este artículo ha sido publicado en el International Journal of Cognitive Education and Psychology. Para la publicación en este anuario se ha contado con el permiso de la dirección de dicho Journal y de los autores. 


\section{Resumen}

En el estudio 1 se ha evaluado la eficacia de dos programas de intervención lectora (uno de tipo fonético y otro de tipo inductivo), mientras que en el estudio 2 se aplicó el programa PREP (Programa de Mejora de la Lectura PASS). La muestra estuvo integrada por 63 niños indios americanos, diagnosticados como débiles lectores, escolarizados en el curso tercero y cuarto de la enseñanza primaria. Las principales variables dependientes en el estudio 1 fueron los cambios producidos entre el pretest y el postest, evaluados por un test de lectura de palabras y por otro de decodificación de palabras. Las otras variables dependientes fueron evaluadas por un test de conciencia fonológica, de velocidad de nominación rápida, así como por el test PASS que mide la planificación, la atención, el procesamiento simultáneo y el procesamiento sucesivo. Los resultados del estudio 1 mostraron una mejora significativa de las dos tareas de lectura implicadas en la intervención sobre el aprendizaje inductivo, en aquellos niños cuyos niveles se situaban por debajo de la mediana en el pretest en comparación a los que se situaban por encima de la mediana. El programa que enfatizaba el aprendizaje de sonidos tuvo un resultado similar, pero sobre una sola tarea de lectura: la decodificación de palabras. Los resultados se presentan como modos de intervención lectora con niños afectos de dificultades persistentes en lectura. En el estudio 2 las principales variables dependientes estaban integradas por la lectura de palabras, la decodificación de palabras y la comprensión de extractos de textos. Los resultados han mostrado que los participantes que se han beneficiado de la intervención basada en el programa PREP obtuvieron una mejora continua de sus competencias lectoras, especialmente en la comprensión.

Palabras clave: Dificultades aprendizaje de la lectura, Efectos de dos programas de intervención.

Reading can be considered as an interplay between knowledge base, and proximal and distal cognitive processes. The most frequently recognized proximal cognitive processes in word reading are phonological processes, such as phonological awareness and rapid naming speed (e.g., Adams, 1990; Goswami \& Bryant, 1990; Kirby, Parrila, \& Pfeiffer, 2003; Manis, Doi, \& Bhadha, 2000; Parrila, Kirby, \& McQuarrie, 2004; Scarborough, 1998; Share \& Stanovich, 1995; Stanovich, 1992; Torgesen, Wagner, Rashotte, Burgess, \& Hecht, 1997; Wolf \& Bowers, 1999). The distal cognitive processes are more general and modality unspecific underlying cognitive processes and are expected to enable the development of proximal processes. Among the distal processes, working memory and a broader set of cognitive processes comprising Planning, Attention, Simultaneous, and Successive (PASS) processes have been considered for some time (e.g., Das, Mishra, \& Kirby, 1994; Das, Naglieri, \& Kirby, 1994; Kirby, Booth, \& Das, 1996; Naglieri \& Reardon, 1993; Papadopoulos, 2001). Deficits in word reading, in particular, can result from difficulties with any or all of the above, proximal and distal cognitive processes. Hence, the rationale for constructing a remedial program for the enhancement of reading should include training to develop both types of processes.

Recently, there has been an increase in intervention studies that have emphasized direct instruction on phonological awareness, letter-name and letter-sound knowledge, and whole-word reading (e.g., Blachman et al., 2004; Engelmann \& Bruner, 1995b; Foorman et al., 1997; O’Shaughnessy \& Swanson, 2000; Torgesen, Wagner, Rashotte, Alexander, \& Conway, 1997). However, at the same time, there is a growing concern 
regarding the effectiveness of such training (e.g., Blachman, 1997; Bus \& van IJzendoorn, 1999; Fawcett, Nicolson, Moss, Nicolson, \& Reason, 2001; Schneider, Ennemoser, Roth, \& Küspert, 1999). For example, Wagner, Torgesen, Laughon, Simmons, and Rashotte (1993) concluded that phonological processing training, by itself, provides, at best, limited improvement in reading ability. In a meta-analysis of phonological processing training studies, Bus and van IJzendoorn (1999) reported that phonological processing explained approximately $12 \%$ of the variance in word reading immediately following remediation, and the long-term effect is even smaller. In addition, program success was not determined by length of treatment, number of treatment sessions, and group size; rather how early the treatment was initiated was of overriding importance. We mention these not because we wish to enter into controversies surrounding the technique of direct instruction, and the limited success of phonics-based programs; rather, these may provide a counterpoint for an inductive learning approach to reading remediation.

The PASS Reading Enhancement Program (PREP) was developed as an inductive learning remedial program based on the PASS model of cognitive functioning (Das, Naglieri et al., 1994). PASS proposes that cognition is organized in three systems. The first is the Planning system, which involves the executive control system responsible for controlling and organizing behavior, selecting or constructing strategies, and monitoring performance. The second is the Attention system, which is responsible for maintaining arousal levels and alertness and for ensuring focus on appropriate stimuli. The third system is the information processing system, which employs simultaneous and successive processing to encode, transform, and retain information. In Simultaneous processing, the relationship between items and their integration into whole units of information is what is coded, while in Successive processing, information is coded so that the only links between items are sequential in nature (see Das, Naglieri et al., 1994, for a detailed description). The goal of PREP is to improve information processing strategies, especially Simultaneous and Successive processing, which are believed to underlie reading (e.g., Das, Georgiou, \& Janzen, 2008; Joseph, McCachran, \& Naglieri, 2003; Naglieri \& Reardon, 1993; Naglieri, \& Rojahn, 2004).

PREP remediation is structured in such a way as to promote inductive inferencing and internalization of principles and strategies rather than deductive rule learning (Campione \& Brown, 1987; Das, Mishra, \& Pool, 1995). Such a procedure encourages «ownership» of the strategies that the individual can apply, thereby ensuring transfer to broader aspects of reading. In contrast to direct instruction programs, such as Reading Mastery (Engelmann \& Bruner, 1995a, 1995b), PHAST (e.g., Lovett, Lacerenza, \& Borden, 2000) or RAVE-O (Wolf, Miller, \& Donnelly, 2000), PREP avoids explicit teaching of specific reading skills.

PREP consists of eight tasks, which vary considerably, both in content and in what they require from the child. All tasks involve a global training component and an additional curriculum-related bridging component. The global component consists of structured nonreading tasks that require the application of simultaneous or successive strategies. These tasks also provide children with the opportunity to internalize strategies in their own way, thus facilitating transfer. The bridging component involves the same cognitive demands as its global component, and provides training in simultaneous and successive progressing strategies that are closely linked to reading and spelling (Das, Naglieri et al., 1994). 
The cumulative weight of evidence collected over several years of research using PREP has produced positive results with respect to word reading, word decoding, and reading comprehension tasks in English (see, e.g., Brailsford, Snart, \& Das, 1984; Das, Mishra et al., 1994; Janzen, 2000; Papadopoulos, Das, Parrila \& Kirby, 2003), in Greek (Papadopoulos, Charalambous, Kanari, \& Loizou, 2004), and in Spanish (Molina, Garrido, \& Das, 1997). For example, Parrila, Das, Kendrick, Papadopoulos, and Kirby (1999) administered PREP and a «meaning-based» remediation program that emphasized storytelling and meaning extraction to 58 Grade 1 Canadian students experiencing reading difficulties for a total of 18 sessions of 20-minute duration each. Results showed a significant improvement of reading (real and pseudo words) for the PREP group. The gains were greater than for the meaning-based training group. A follow-up study (Papadopoulos et al., 2003) of the same children in Grade 2 showed that the gains made in Grade 1 were somewhat reduced compared to the children receiving normal classroom instruction. The most interesting part of the follow-up study concerned 24 children who failed to gain either from PREP or meaning-based instruction-they received intensive remediation sessions on PREP. Sessions were conducted daily for 30 minutes in a one-on-one session (not two to three for one instructor as in the previous study), for a total of 20 sessions over 4 weeks. Results showed significant improvements in both single word reading as well as single word decoding for the group, as well as improvement in two phonological tasks (Phoneme Elision and Sound Isolation). The two above studies did not have a competing program for direct instruction in phonics. Because phonics or its broader approach nestled in phonological recoding might be an appropriate contender for improvement of word decoding, we included that in the present study as an alternate treatment.

\section{Overview of the Present Study}

The present study was motivated by the challenge of improving the reading skills of aboriginal children who have experienced several years of reading failure. Statistics reported by the Department of Indian and Northern Development (2005) show chronic school dropout among aboriginal youth. While the reasons for such statistics are necessarily complex, one contributing factor to school failure is early reading failure and our education system's inability to properly identify and assist aboriginal children with persistent reading disabilities. In fact, aboriginal youth have reported that reading difficulties were a contributing factor in their decision to leave school (Dehyle, 1992).

The first question we sought to answer in this study was related to the improvement in reading skills following two competing programs of intervention. Our study compared the efficacy of an inductive learning program, PREP, to a «phonics-based» program $(\mathrm{PB})$ that provided direct instruction of phonological processes. The PB program served as a treatment control. The independent variables, then, were the two types of intervention. The major dependent variables were reading measures for single word reading and single word decoding.

We examined whether there was a significant improvement from pre- to post-intervention assessments. If indeed there are improvements, then for which program and on which dependent variable? It might be expected that a direct instruction approach that 
focuses on phonics would have an effect on word decoding. On the other hand, an inductive strategy-based training, being a holistic approach, may or may not show a strong improvement in word decoding. Another question we asked was, Considering, as we must, the initial level of performance against which we measure improvement, would it be reasonable to expect that within each group those participants who are relatively weaker in word reading/decoding would benefit more from intervention than those who are relatively stronger?

The second question concerned the improvement on the proximal cognitive skills of phonological awareness and rapid naming speed, which were also used as dependent variables. If reading and the proximal variables that are related to reading go hand in hand, any intervention that enhances one should enhance the other.

Previous research relating PASS to reading have shown a strong link between Successive processing and word reading in beginning readers and later (Das, Naglieri et al., 1994). Such improvement may be expected, if we accept that some of the PASS processes are used in acquisition of reading (e.g., Das et al., 2008; Joseph et al., 2003; Papadopoulos, 2001). Thus, we questioned whether intervention type would lead to improvements in PASS processes.

\section{METHOD}

\section{Participants}

In December of the school year, students in Grades 3 and 4 attending a reservation school in Western Canada were tested on standardized reading and cognitive measures. Children who scored $1 S D$ or more below the mean on either the word identification or pseudoword reading tests were randomly assigned to one of the two treatment groups (PREP or PB). The two treatment groups did not differ from each other on Word Identification $(p=n s)$ or Pseudoword Decoding $(p=n s)$ tests at pretest, but were significantly poorer than a «no-risk» control group that consisted of students whose reading scores were within average ( $M=96.95$ for Word Identification and $M=101.62$ for Pseudoword Decoding). The participants' demographics are displayed in Table 1.

\section{Tests and Procedures}

All children were administered phonological awareness, rapid naming, cognitive processing, and reading tests individually by the examiners who were trained in the administration of all protocols. Testing was completed before and after the remediation period. The specific testing protocols are described below.

\section{Phonological Awareness}

Phoneme Elision. The Phoneme Elision task from the Comprehensive Test of Phonological Processing (CTOPP; Wagner, Torgesen, \& Rashotte, 1999) was used as a measure of phonological awareness. This task measures the extent to which an individual can say a word and then say what is left after dropping out designated sounds. The task consists of 20 items. For the first two items, the examiner says compound words and 
TABLE 1: Participant Characteristics

\begin{tabular}{|l|c|c|c|}
\hline Measure & $\begin{array}{c}\text { PB } \\
(n=21)\end{array}$ & $\begin{array}{c}\text { PREP } \\
(n=21)\end{array}$ & $\begin{array}{c}\text { No risk } \\
(n=21)\end{array}$ \\
\hline Male & 11 & 8 & 8 \\
\hline Female & 10 & 13 & 3 \\
\hline Age in months (SD) & $116.43(8.87)$ & $109.95(9.06)$ & $110.14(10.55)$ \\
\hline
\end{tabular}

Note: PB = Phonics-based remediation, PREP = PASS Reading Enhancement Program.

asks the examinee to say the word, and then say the word that remains after dropping one of the compound words. For the remaining items, the individual listens to a word and repeats the word, and then is asked to say the word without a specific sound. The participant's score is the number of correct responses. Wagner et al. reported test-retest reliability of .79 for Phoneme Elision for ages 8 to 17.

Word Segmentation. The Word Segmentation task was adopted from CTOPP as well (Wagner et al., 1999). It consists of 20 items and it measures the ability of an individual to say separate phonemes that make up a word. The examinee is told to repeat a word, then to say it one sound at a time. For example, the examiner tells the examinee to say «book» and then to say it one sound at a time. The participant's score is the number of correct responses. Wagner et al. (1999) reported test-retest reliability of .79 for Word Segmentation for ages 8 to 17.

\section{Rapid Naming Speed}

Object Naming. The Object Naming task from the CTOPP (Wagner et al., 1999) was used as a measure of rapid serial naming. Participants were required to state as quickly as possible the names of six objects (pencil, boat, star, key, chair, fish). On two separate sheets, the six objects were arranged randomly in four rows with nine objects in each row. Prior to beginning the timed naming, each participant was asked to name the objects to ensure familiarity. The two pages were timed separately and the time in seconds to name the objects on both pages was the participant's score. Wagner et al. reported test-retest reliability of .93 for Object Naming for ages 9 to 17.

Color Naming. The Color Naming task was adopted from the CTOPP (Wagner et al., 1999). This task consists of a set of six colors (blue, red, green, black, yellow, and brown) that are displayed in random sequence six times for a total of 36 stimuli. The individual is told to name the colors from left to right as quickly as possible and the total time to complete the task is recorded. Before naming the colors for each of the 36 stimuli, each participant was asked to name the colors in a practice trial. Wagner et al. reported test-retest reliability of .89 for Color Naming for ages 8 to 17 .

Digit Naming. This task was adopted from the CTOPP (Wagner et al., 1999). This task consists of a set of six digits $(4,7,8,5,2,3)$ that are displayed in random sequence six times for a total of 36 stimuli. Subjects are asked to name the digits from left to right as quickly as possible, and the total time to complete the task is recorded. Before nam- 
ing the 36 digits, each participant was asked to name the digits in a practice trial. Wagner et al. reported test-retest reliability of .80 for Digit Naming for ages 9 to 17.

Letter Naming. This task also was adopted from the CTOPP (Wagner et al., 1999). Participants were asked to name as fast as possible the names of six letters (a, n, s, t, k, c). Letters were arranged randomly in four rows of nine letters in each row. As in the other naming speed tasks, children were asked to name the six letters in a practice trial before proceeding to the timed trials. The two pages were timed separately. Wagner et al. reported test-retest reliability of .72 for Letter Naming for ages 8 to 17.

\section{Cognitive Processing Tasks}

The Das-Naglieri Cognitive Assessment System (CAS; Naglieri \& Das, 1997) is an individually administered test of cognitive functioning for children and adolescents ranging from 5 through 17 years of age that was designed to assess the four PASS cognitive processes: Planning, Attention, Simultaneous, and Successive. The four PASS scales and the Full Scale standard scores are set at a mean of 100 and SD of 15. The Basic Battery, which was used for this research project, consists of eight subtests; two subtests per PASS scale. Descriptions of the subtests and scales as well as evidence for the reliability of the individual subtest scores and PASS Full Scale scores are provided in the manual (Naglieri \& Das, 1997). The CAS has good psychometric properties with average internal consistency alpha values for the Basic Battery as follows: Planning $=.85$, Attention $=.84$, Simultaneous $=.90$, Successive $=90$, and Full Scale $=.87$.

The Planning subtests of the Basic Battery of CAS include Matching Numbers and Planned Codes. In the Matching Numbers subtest, children are presented with four pages containing eight rows of numbers. For each row, the child is instructed to underline the two numbers that are the same. The time and number correct for each page is recorded and the subtest score is calculated by combining both time and number correct. The Planned Codes subtest contains two pages, each with a distinct set of codes arranged in seven rows and eight columns. At the top of each page is a legend, which indicates how letters relate to simple codes (e.g., $\mathrm{A}=\mathrm{OX}, \mathrm{B}=\mathrm{XX}, \mathrm{C}=\mathrm{OO}$ ). The child is instructed to fill in the correct code beneath each corresponding letter in any manner he or she chooses. The subtest score is calculated by combining both the time and number correct for each page.

The Attention subtests of the Basic Battery of the CAS include Expressive Attention and Number Detection. For Expressive Attention, children 8 years and older are given three pages to complete. For the first page, the child reads color words (i.e., Blue, Yellow, Green, and Red). The words are presented in a quasi-random order. On the second page, the child is instructed to name the colors of a series of rectangles printed in the aforementioned colors. On the third page, the color words are printed in a different ink color than the color the words name (e.g., the word Red may appear in blue ink). The task on the third page is for the child to name the color of ink-while not saying the color word. The subtest score is calculated using time and number correct. The Number Detection subtest asks children to find the target stimuli (e.g., the numbers 1, 2 , and 3 printed in an open font) among many distracters (e.g., the same numbers printed in a different font). The subtest score is a ratio of accuracy (total number correct minus the number of false detections) to total time taken to complete all items. 
The Simultaneous subtests of the Basic Battery of the CAS include Nonverbal Matrices and Verbal Spatial Relations. Nonverbal Matrices items present a variety of shapes and geometric designs that are interrelated through spatial or logical organization. For each item, the child is required to decode the relationships and choose the best of six possible answers to complete the grid. The subtest score is the total number correct. Verbal Spatial Relations measures the comprehension of logical and grammatical descriptions of spatial relationships. In this subtest, the child is presented with six drawings, arranged in a specific spatial manner, and a printed question. Then, the child is instructed to choose one of the six drawings that best answers the question within the 30 -second time limit. The subtest score is calculated by adding up the total number of items answered correctly.

The Successive subtests of the Basic Battery of the CAS include Word Series and Sentence Repetition. In Word Series, the examiner reads the child a series of words and then asks the child to repeat the words in the same order. This subtest uses the following nine single-syllable, high-frequency words: Book, Car, Cow, Dog, Girl, Key, Man, Shoe, and Wall. The presentation rate is one word per second. The subtest score is the total number of words series correctly repeated. For Sentence Repetition the child is read 20 sentences aloud and is asked to repeat each sentence exactly as presented. The sentences are composed of color words (e.g., "The blue yellows the green»), which reduces the influence of simultaneous processing and removes semantic meaning for the sentences. The subtest score is the total number of sentences repeated correctly.

\section{Word and Pseudoword Reading Measures}

The Woodcock-Johnson Tests of Achievement (Woodcock, McGrew, \& Mather, 2001) was used to assess word reading ability. The Word Identification subtest involves the reading of individual words with some early items that require correct letter identification. Word Attack is a phonetic decoding task in which the child is required to pronounce nonsense words. All reading tests scores were calculated using the accompanying computer scoring program. Scores in reference to a norm group reported for this paper were relative to age-norms. Woodcock et al. (2001) reported split-half reliabilities of .98 for Word Identification and .94 for Word Attack.

\section{Instructor Training}

Three instructors, all elementary school teachers, administered the interventions. A phonics-based program had been used by the school resource teacher for several years. We chose to compare this program with the cognitive-based program since it satisfied our criterion of direct instruction of phonics skills, and the teacher had developed and followed an instruction manual. The other two instructors, hired for the study, were trained to administer PREP following manual instructions. The first and fourth authors, a researcher and clinical psychologist who have used the remediation programs in previous studies and in a private practice setting, trained the instructors. The researchers also conducted ongoing supervision of remedial work in both the PB and PREP programs. 


\section{Treatment Integrity}

During the remediation, the fourth author visited the schools weekly, completing a treatment integrity checklist each visit and recording the daily treatment integrity checklists kept from each instructor separately at the end of each intervention session. In assessing treatment integrity, the occurrence or nonoccurrence of major treatment components was evaluated after each training session. The level of treatment integrity was obtained by calculating the percentage of treatment components implemented as designed over the course of the study. Throughout interventions and across instructors treatment integrity was very high with $95 \%$ fidelity of essential instructional practices.

\section{Remediation Programs}

\section{Phonics-Based (PB) Remediation Program}

The program is comprised of a variety of phonics tasks compiled by the school resource teacher that had been used in the school for several years. The tasks were similar to many commercially available phonics programs. The instructor completed the program following a manual.

\section{Inductive Learning Program (PREP: PASS Reading Enhancement Program)}

The program consists of four successive processing modules and four simultaneous processing modules, each involving a global and curriculum-related bridging component. The global components comprise structured non-reading tasks requiring application of successive or simultaneous strategies while the bridging component involves the same processing and strategy use in activities linked to reading and spelling. The instructors administered the program following the scripted manual. The four successive modules were completed first followed by the simultaneous modules.

Following pretesting (December) the remediation programs were administered to children in small groups (3-4 students), twice weekly for a total of 20 sessions. Each session was approximately 40 minutes in length for a total of 13-1/2 hours of instruction. However, absenteeism resulted in some students attending less than the 20 sessions resulting in an average of 11-1/2 hours of total instruction. Posttesting was completed immediately after the completion of the remediation programs (May).

\section{Statistical Analyses}

Unless otherwise stated, standard or scaled scores were used to examine changes in the dependent variables. Effect sizes are reported as partial eta squared $\left(\eta_{\mathrm{p}}{ }^{2}\right)$ coefficients. According to general guidelines for interpreting partial $\eta_{\mathrm{p}}{ }^{2}$, values between 0 and .25 would be considered small, values between .26 and .50 would be considered moderately large, and values above .50 would be considered large (Cohen, 1988). Post hoc differences were examined using the Scheffe test. Means and standard deviations for all measures at pretest and posttest are presented in Table 2 (next page). For some measures, data are not available for all participants; this has been noted in Table 2. 
TABLE 2: Descriptive Statistics for all Measures for Each Group at Pretest and Posttest

\begin{tabular}{|c|c|c|c|c|c|c|}
\hline \multirow[b]{2}{*}{ Measure } & \multicolumn{2}{|c|}{$P B(n=21)$} & \multicolumn{2}{|c|}{$\operatorname{PREP}(n=21)$} & \multicolumn{2}{|c|}{ No-Risk $(n=21)$} \\
\hline & Pretest & Posttest & Pretest & Posttest & Pretest & Posttest \\
\hline Phonological Awareness & \multicolumn{2}{|c|}{$(\mathrm{n}=18)$} & \multicolumn{2}{|c|}{$(\mathrm{n}=19)$} & & \\
\hline Segmenting Words & $\begin{array}{l}7.00 \\
(2.06) \\
10.44 \\
(2.41)\end{array}$ & $\begin{array}{c}7.67 \\
(2.14) \\
9.44 \\
(2.28)\end{array}$ & $\begin{array}{l}7.42 \\
(1.86) \\
11.53 \\
(1.77)\end{array}$ & $\begin{array}{c}7.53 \\
(1.84) \\
10.47 \\
(.90)\end{array}$ & & \\
\hline Rapid Naming & \multicolumn{2}{|c|}{$(\mathrm{n}=19)$} & \multicolumn{2}{|c|}{$(\mathrm{n}=21)$} & \multicolumn{2}{|c|}{$(\mathrm{n}=21)$} \\
\hline $\begin{array}{l}\text { Alphanumeric } \\
\text { (Digits + Letters) } \\
\text { Non-alphanumeric } \\
\text { (Colors + Objects) }\end{array}$ & $\begin{array}{c}7.36 \\
(2.33) \\
6.76 \\
(3.03)\end{array}$ & $\begin{array}{c}7.34 \\
(2.00) \\
6.31 \\
(2.89)\end{array}$ & $\begin{array}{c}8.12 \\
(2.05) \\
7.28 \\
(2.74)\end{array}$ & $\begin{array}{l}8.05 \\
(1.71) \\
7.55 \\
(2.29)\end{array}$ & $\begin{array}{l}10.43 \\
(6.41) \\
7.07 \\
(2.78)\end{array}$ & $\begin{array}{c}9.02 \\
(2.39) \\
7.74 \\
(2.00)\end{array}$ \\
\hline Reading Measures & \multicolumn{2}{|c|}{$(\mathrm{n}=19)$} & \multicolumn{2}{|c|}{$(\mathrm{n}=21)$} & \multicolumn{2}{|c|}{$(\mathrm{n}=21)$} \\
\hline Word Identification & $\begin{array}{c}78.38 \\
(12.39)\end{array}$ & $\begin{array}{c}81.19 \\
(12.96)\end{array}$ & $\begin{array}{c}80.57 \\
(10.51)\end{array}$ & $\begin{array}{l}83.43 \\
(9.16)\end{array}$ & $\begin{array}{l}96.95 \\
(6.72)\end{array}$ & $\begin{array}{l}97.76 \\
(9.30)\end{array}$ \\
\hline \multirow[t]{2}{*}{ Word Attack } & \multicolumn{2}{|c|}{$(\mathrm{n}=21)$} & \multicolumn{2}{|c|}{$(\mathrm{n}=20)$} & \multicolumn{2}{|c|}{$(\mathrm{n}=21)$} \\
\hline & $\begin{array}{c}86.33 \\
(12.74)\end{array}$ & $\begin{array}{l}92.81 \\
(7.53)\end{array}$ & $\begin{array}{c}87.85 \\
(12.43)\end{array}$ & $\begin{array}{l}92.40 \\
(6.48)\end{array}$ & $\begin{array}{r}101.62 \\
(8.77)\end{array}$ & $\begin{array}{c}102.81 \\
(8.00)\end{array}$ \\
\hline Cognitive Measures & \multicolumn{2}{|c|}{$(\mathrm{n}=21)$} & \multicolumn{2}{|c|}{$(\mathrm{n}=20)$} & \multicolumn{2}{|c|}{$(\mathrm{n}=21)$} \\
\hline Planning Scale & $\begin{array}{c}86.48 \\
(11.79)\end{array}$ & $\begin{array}{c}87.86 \\
(10.74)\end{array}$ & $\begin{array}{l}92.50 \\
(7.44)\end{array}$ & $\begin{array}{l}95.15 \\
(8.45)\end{array}$ & $\begin{array}{c}88.24 \\
(10.13)\end{array}$ & $\begin{array}{c}97.86 \\
(10.61)\end{array}$ \\
\hline Attention Scale & $\begin{array}{c}90.95 \\
(11.28)\end{array}$ & $\begin{array}{c}98.14 \\
(10.67)\end{array}$ & $\begin{array}{c}96.70 \\
(10.79)\end{array}$ & $\begin{array}{r}101.35 \\
(7.51)\end{array}$ & $\begin{array}{c}95.76 \\
(10.47)\end{array}$ & $\begin{array}{r}100.29 \\
(8.32)\end{array}$ \\
\hline Successive Scale & $\begin{array}{c}83.00 \\
(11.94)\end{array}$ & $\begin{array}{c}85.62 \\
(10.74)\end{array}$ & $\begin{array}{c}86.25 \\
(12.26)\end{array}$ & $\begin{array}{c}91.10 \\
(11.64)\end{array}$ & $\begin{array}{c}89.81 \\
(11.75)\end{array}$ & $\begin{array}{l}92.29 \\
(9.63)\end{array}$ \\
\hline Simultaneous Scale & $\begin{array}{l}89.86 \\
(8.35)\end{array}$ & $\begin{array}{c}91.29 \\
(11.22)\end{array}$ & $\begin{array}{c}94.45 \\
(13.14)\end{array}$ & $\begin{array}{c}94.90 \\
(12.16)\end{array}$ & $\begin{array}{c}94.76 \\
(11.54)\end{array}$ & $\begin{array}{c}95.67 \\
(11.73)\end{array}$ \\
\hline
\end{tabular}

Note: PB = Phonics-based remediation, PREP = PASS Reading Enhancement Program, No-Risk = Control Group. (SD's and n's are in parentheses).

\section{STUdY 1: RESUlTS}

\section{Remediation Program Analyses}

\section{Reading Measures}

Separate 3 (group: PB, PREP, No-Risk) x 2 (time: Pretest, Posttest) repeated measures ANOVAs were conducted using standard scores for Word Identification and Word Attack. The results revealed a significant main effect of time for Word Identification, $F(1$, 
$60)=5.85, p=.02, \eta_{\mathrm{p}}{ }^{2}=.09$, and Word Attack, $F(1,59)=15.17, p<.001, \eta_{\mathrm{p}}{ }^{2}=.20$, and a significant main effect of group for Word Identification, $F(2,60)=20.15, p<.001, \eta_{\mathrm{p}}{ }^{2}=$ .40 , and Word Attack, $F(2,59)=14.05, p<.001, \eta_{\mathrm{p}}{ }^{2}=.32$. The Group x Time interaction was not significant for either reading task. Post hoc analyses showed that the relationship among groups on both reading measures was consistent with the pretest findings, where the No-Risk group achieved higher scores than both the PB and the PREP group.

Gains scores. In order to look more closely at possible differential effects of the direct instruction versus inductive learning programs, we examined gains in reading scores for the PB and PREP participants based on ratio scores for rate of improvement/hours of instruction. We chose this parameter to evaluate the success of the intervention since Torgesen (2002) stated that for the most part reading remediation programs for older children who are failing to read tend to stabilize the problem rather than close the gap.

Torgesen (2002) had conducted a meta-analysis of several reading programs that provided intensive (30-80 hours instruction) remediation, and reported that the average improvement across studies for word reading was a 2 point standard score point gain and for pseudoword reading a 3-4 point gain. Following Torgesen, we calculated a ratio score to determine standard score point gain per hours of instruction. Due to several factors, our remediation ( $M=11.5$ hours) was not intensive; nonetheless, our results revealed that improvements for word reading and word decoding were above the gains suggested by Torgesen for both the PB and the PREP group (see Table 3 ).

TABLE 3: Standard Score Improvements for PB and PREP

Participants Based on Hours of Instruction

\begin{tabular}{|l|c|c|c|c|}
\hline & \multicolumn{2}{|c|}{ PB } & \multicolumn{2}{c|}{ PREP } \\
\hline & WID & WAT & WID & WAT \\
\hline Average Standard Score Improvement & $2.81^{\mathrm{a}}$ & $6.48^{\mathrm{a}}$ & $2.86^{\mathrm{a}}$ & $4.55^{\mathrm{a}}$ \\
\hline
\end{tabular}

Note: PB = Phonics- based remediation, PREP = PASS Reading Enhancement Program; WID = Word Identification; WAT = Word Attack. Subtests all taken from the Woodcock-Johnson III Tests of Achievement. Benchmarks to support utility of remediation programming suggested by Torgesen (2002, p. 100): WordID = 2 points, WordAT = 3-4 points, PassComp $=1.3$ points.

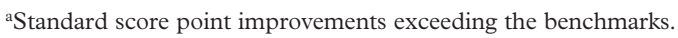

Weaker versus stronger reader groups. Next, we divided the remediation group participants into two groups using median standard scores to create relatively "weaker» and «stronger» reader groups and then looked at each group separately to see if there was a differential effect of remediation. For Word Identification we used a standard score cut-off of 84 (Median $=84$ ). In the PB group there were 10 students in the "weaker reader» group and 11 in the «stronger reader» group. For the PREP group there were 11 students in the "weaker reader» group and 10 in the «stronger reader» group. We then conducted separate Group (Weaker/Stronger) x Time (Pre/Post) repeated measures ANOVAs for the PB and PREP participants. For the PB group there were no significant main effects of time $(p=n s)$ or Group $\mathrm{x}$ Time interaction $(p=n s)$. Results for 
the PREP group show a significant main effect for time, $F(1,19)=7.31, p=.02, \eta_{\mathrm{p}}{ }^{2}=$ .28 , but the Group x Time interaction was not significant $(p=.08)$.

For Word Attack, we used a standard score cut-off of 89 (Median $=90$ ). In the PB group there were 11 students in the «weaker reader» group and 10 in the «stronger reader» group. For the PREP group there were 10 students in the "weaker reader» group and 10 in the «stronger reader» group. We again conducted separate Group x Time repeated measures ANOVAs for the PB and PREP participants. For PB, significant main effects were found for Time, $F(1,19)=20.61, p<.001, \eta_{\mathrm{p}}{ }^{2}=.52$, and for the Group x Time interaction, $F(1,19)=16.41, p<.001, \eta_{\mathrm{p}_{2}}^{2}=.46$. Results for PREP also revealed main effects of Time, $F(1,18)=7.45, p=.05, \eta_{\mathrm{p}}{ }^{2}=.29$, and of Group x Time interaction, $F(1,18)=$ 9.92, $p=.01, \eta_{\mathrm{p}}{ }^{2}=.35$. Thus, while PREP demonstrated improvements for the weaker readers in both single word reading and word decoding tasks, the PB remediation showed improvements for the weakest readers only in word decoding task.

\section{Proximal Measures Analyses}

In the next section we present results for proximal measures, namely phonological awareness (Elision and Segmenting Words), and rapid naming speed (alphanumeric [digits + letters] and non-alphanumeric [colors + objects]).

\section{Phonological Awareness}

Data were available for the two remediation groups only. Prior to remediation the two groups were performing similarly across tasks (Elision $p=n s$, Segmenting Words $p=$ $n s$ ). A 2 (group: PB, PREP) x 2 (time: pre-, post-) MANOVA with repeated measures on the dependent variables (Elision and Segmenting Words scaled scores) showed a significant main effect of time, Wilks's Lambda $=.80, F(2,34)=4.23, p<.05$. The main effects for group and the Group x Time interaction were not significant. Follow-up univariate tests showed that the main effect of time was significant only for the Segmenting Words task, $F(1,35)=6.92, p=.01, \eta_{\mathrm{p}}{ }^{2}=.16$, where both groups scored lower at posttest than at pretest (see Table 2), an unexpected result indeed.

\section{Rapid Naming Speed}

There were no significant pretest differences among groups on rapid naming tasks (alphanumeric $p=n s$ ) and (non-alphanumeric $p=n s$ ). A 3 (group: PB, PREP, No-Risk) $\mathrm{x}$ 2 (time: pre-, post-) MANOVA with repeated measures on the dependent variables (alphanumeric and non-alphanumeric rapid naming scaled scores) approached significance for group $(p<.05)$. The main effect for time and the Group x Time interaction were not significant. Remediation had no effect on these measures.

\section{Distal Measures Analyses}

\section{Cognitive Processing Measures}

Prior to remediation there were no significant differences among the three groups on any of the four PASS processes. A 3 (group: PB, PREP, No-Risk) x 2 (time: pre-, post) 
repeated measures MANOVA for PASS scales (Planning, Attention, Successive, and Simultaneous standard scores) showed a significant main effect of time, Wilks's Lambda $=.59, F(4,56)=9.90, p<.001$. The Group x Task and Group x Time interactions were not significant. Follow-up univariate tests for time showed a significant effect on three of the scales: Planning, $p<.001$, Attention, $p<.001$, and Successive processing, $p<.01$, where means across all groups were higher on these three scales. This was not the case for the Simultaneous scale.

\section{Study 1: Discussion}

In our present study we investigated the effectiveness of a phonics-based (PB) and an inductive learning remediation program (PREP) with a group of First Nations children who were poor readers in spite of 3-4 years of formal reading instruction. We included a competing treatment control group that received direct instruction in a PB reading remediation program for the same number of hours as the PREP group. This had never been done in our previous studies on PREP reviewed in the introduction. The closest competing group in those studies was a meaning-based intervention. Thus, intervention by direct instruction on phonological processing as a comparison offered a tough challenge to PREP. In addition, we compared the outcome of the two kinds of intervention with a «no-risk» control group of children (i.e., no-risk, average readers) who received the usual classroom instruction. This group was used as a normal-group comparison, in order to determine whether improvements made by children in the remedial groups bridged the gap or whether in spite of the interventions their reading disabilities could be stabilized only at a lower level. In the following sections we will discuss improvements across the measures used to evaluate outcomes in answer to our research questions.

In regard to the comparison between the PREP and the PB intervention program, global examination revealed no differential effects for type of remediation. However, when we looked at improvements of weaker versus stronger readers within each group, differential effects of remediation type emerged. For word reading we found no differential effects for PB but for PREP we found that across time the weaker readers made greater gains. For word decoding, we found differential effects for both remediation types in favor of the weaker readers, and for both kinds of remediation, moderate effects sizes were found. These are important findings, particularly since we provided a very short period of intervention. Tracking the effect of treatment by calculating improvement rates per hours of instruction, we found that improvements in both word reading and word decoding were above the gains suggested by Torgesen (2002) for both the PB and PREP remediation programs. This result was not unexpected for the direct instruction, particularly for word decoding skills; however, the inductive, strategybased program also resulted in improvements above Torgesen's benchmarks.

Given the population of children we worked with, in which there is a history of poor school attendance, and differing cultural experiences related to home literacy, these improvements have an added importance. Our study revealed that the inductive learning program produced results that were very close to those achieved by the direct instruction PB program for word decoding and were better than the direct instruction program for word reading even though reading and decoding skills were never taught 
directly. However, it will be important to determine whether instructional efforts that fall in the range of 30-80 hours as cited in the research literature show additional benefits for either the direct instruction or inductive learning programs.

With respect to phonological awareness, data were available for the two treated groups only. Relationships among groups remained similar over the course of the study. The one finding of interest was that mean scores for both groups on the Segmenting Words task was lower at posttest. However, it should be noted that the lower scores were at or close to the age expected mean $(M=10)$ across both groups (see Table 2). With respect to the Elision task, means remained in the low average range for both groups across the course of the study. It is possible that a longer remediation period could have produced more significant changes. Alternatively, it is also possible that the particular measures of phonological awareness used in our study were not sensitive enough to reflect either phonological difficulties or improvements, especially since word decoding skills for both groups improved from pre- to posttesting such that group means were within the average range (PB: $M=92.81$; PREP: $M=92.40$ ). Perhaps alternate phonological awareness tasks (e.g., detection of alliteration, onset and rime discrimination) might be good indicators for older children with persistent reading disabilities. When readers are performing at such high levels of decoding, a measure of phonological awareness may suffer a loss in sensitivity.

In terms of the rapid naming tasks, relationships within and among groups remained similar over the course of the study. Statistical analysis of the alphanumeric task (letters and digits) approached significance $(p=.054)$ and possibly with a longer intervention period or larger sample would have reached significance. These suggestions at best are speculative at this stage pending both an empirical study and a theoretical clarification. However, our findings are in line with findings of previous studies showing that rapid naming is hard to improve (e.g., de Jong \& Vrielink, 2004; Thaler, Ebner, Wimmer, \& Landerl, 2004; Wolf, Miller et al., 2000). Theoretically, the variables that intervene in the rapid presentation of a letter or digit and its articulation are yet to be fully identified and their contribution to reading need to be better understood (e.g., Georgiou, Parrila, \& Kirby, 2006; Wolf, Bowers, \& Biddle, 2000).

Improvements in cognitive processes, distal measures, were observed for both groups at posttest. However, since the Group x Time interaction was not significant, we did not proceed to examine it further in univariate analysis. We had expected a differential effect in favor of the inductive learning program, given the focus on underlying cognitive processes. The PREP instructors noticed that the children were often competitive and there were behavior/conduct issues that needed to be addressed in every session. Given the focus on inductive learning, impact of PREP under these constraints was likely reduced in achieving both learning and transfer of cognitive strategies. Additionally, in our present study we administered the remediation programs to groups of 4-5 students, which may not be optimal for inductive learning.

\section{STUDY 2: PREP BOOSTER}

At the end of Study 1 we realized that PREP participants had not received the program for the recommended hours of instruction, that is 16-20 hours as in previous studies (mean hours in Study $1=11.50$, range $=6$ to 13.3 hours). We argued that for disadvan- 
taged children such as we tested, 20 hours of instruction could stand at least a chance of showing improvements, so our goal was to provide these students with additional instructional hours to better determine the effects of the cognitive-based remediation. In a previous study we had adopted the procedure of giving booster sessions of PREP to students who did not gain in reading following a first attempt (Papadopoulos et al., 2003). The group of students who did not improve comprised those who had been administered either PREP or a meaning-based (whole language) remediation program; these students were given an additional 10 hours of PREP. These students in Grade 3 showed significant improvement in word decoding and passage comprehension. Therefore, we were encouraged to try this procedure with the present sample.

\section{Participants}

We implemented the PREP booster remediation at the beginning of the next school term (September) when the students were in Grades 4 and 5. Of the 23 PREP participants from Study 1, only 17 remained in the school. Those 17 students became the participants in Study 2. Eight of the students were in Grade 4 and nine were in Grade 5. There was no PB group in Study 2, consistent with the objectives of the study.

\section{Measures}

The reading, phonological awareness, and rapid naming measures remained the same as those administered in Study 1. We gave an additional reading measure, the Passage Comprehension (PassComp) subtest of the Woodcock-Johnson III Test of Achievement (WJ III; Woodcock et al., 2001). Cognitive measures were not re-administered since this group was well within the normal range following Study 1.

\section{Procedure}

Students were seen at the school in groups of 3-4 twice weekly for 40 minute sessions. For any student who was absent the facilitator provided a make-up session. The total number of sessions possible within constraints of the school and cultural holidays/ events was 14 (9 hours of instruction), bringing the total sessions including Study 1 to 34 sessions (22 hours).

\section{STUdy 2: Results}

\section{PREP Booster Analysis}

Descriptive statistics for Time 1 (pretest Study 1), Time 2 (posttest Study 1) and Time 3 (posttest PREP booster) are displayed for the three reading, two phonological, and two rapid naming measures in Table 4. Repeated measures ANOVA values are provided for all measures and are shown as a function of improvements from Time 1, 2, and 3. Effect sizes and improvement patterns are shown only for measures with statistically significant improvements. Standard or scaled scores were entered for all dependent variables unless otherwise stated. Since improvement in reading through additional time on PREP was our objective for Study 2, we will not report the results of tests other than reading and comprehension. 
Significant improvements (see Table 4) were found from Time 1 - Time 3 for two reading measures (WordID and WordAT) with medium effect sizes. Significant improvements were also shown from Time 2 - Time 3 for the two rapid naming measures (alphanumeric and non-alphanumeric) with large effect sizes. We did not observe statistically significant improvements on the reading comprehension measure (Passage Comprehension) for standard scores at the .05 level. However, given the small sample size, we examined raw scores for this measure and did observe a significant improvement $F(1,17)=6.06, p<.05$, with a medium effect size $\left(\eta_{\mathrm{p}}^{2}=.26\right)$.

TABLE 4: Time 1, 2, and 3 Means, Standard Deviations, ANOVA Values, Effect Sizes, and Improvement Patterns on Reading, Rapid Naming, and Phonological Measures for PREP Remediation

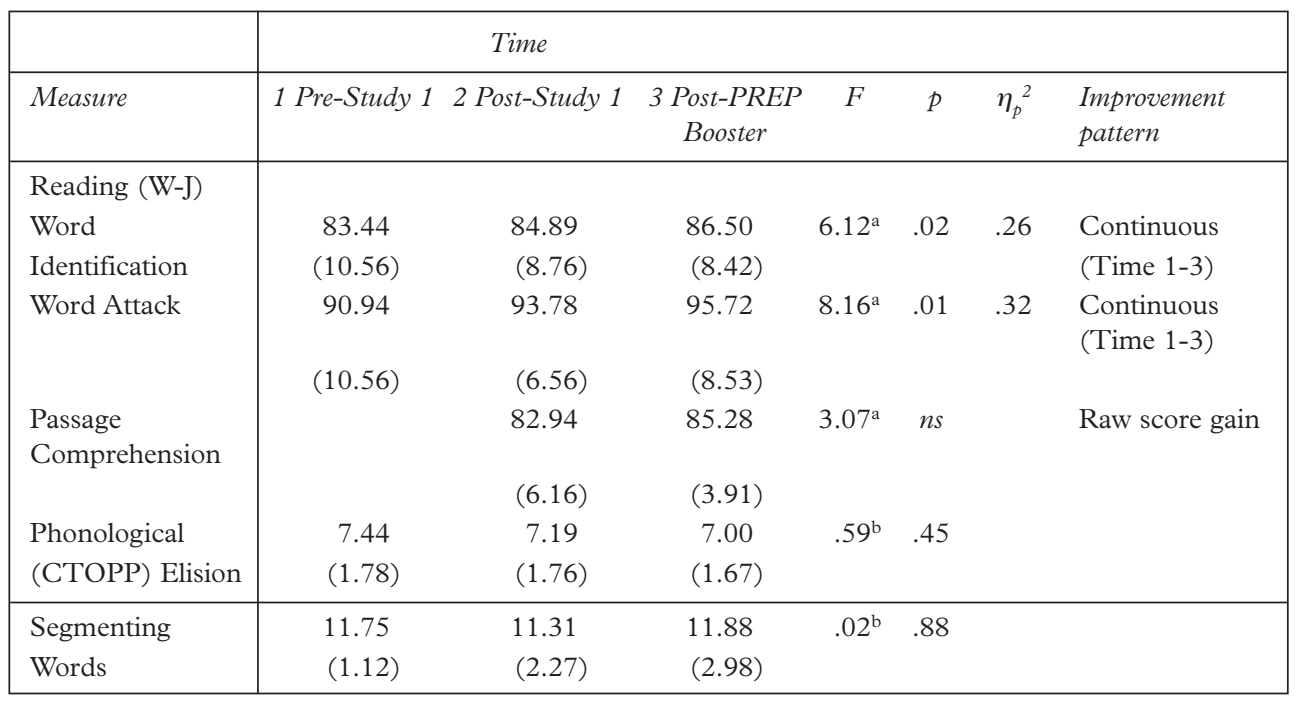

${ }^{\mathrm{a}} d f(1,17)$

${ }^{\mathrm{b}} d f(1,15)$

$\eta_{\mathrm{p}}{ }^{2}$ : small effect $=.00-0.25 ;$ medium effect $=.26-.50 ;$ large effect $=>.50$ (Cohen, 1988).

(SD's are in parentheses).

\section{Tests for Individual Improvement}

Similar to Study 1, we inspected percentiles for single word reading (WordID) and standard score point gains for WordID and WordAT for individual students as well as reading comprehension (PassComp). First, we inspected WordID and PassComp percentile scores at pre- and posttest to determine how many students remained at or below the $5^{\text {th }}$ and $10^{\text {th }}$ percentiles. Recall that at the end of the first study $18 \%$ of the PREP participants remained in these categories. Since we had only 17 of the original participants we first checked the number of students who were in that group. Of the 17 
students, $6(35 \%)$ still remained at or below the $10^{\text {th }}$ percentile. We then examined percentile scores following the PREP booster. Results were as follows: WordID $\left(0-5^{\text {th }}\right.$ percentile [4/17] $23.5 \% /[3 / 17] 18 \%$; $6-10^{\text {th }}$ percentile [2/17] 12\%/[4/17] 23.5\%). These results show that one student moved from the $5^{\text {th }}$ to $10^{\text {th }}$ percentile category resulting in similar percentages of students at or below the $10^{\text {th }}$ percentile before and after additional remediation. For reading comprehension (PassComp) we tested students before and after the PREP booster; the pre-/post percentages of students who were at or below the $10^{\text {th }}$ percentile were as follows: $\left(0-5^{\text {th }}\right.$ percentile $[2 / 17] 12 \% /[0 / 17] 0 \% ; 6-10^{\text {th }}$ percentile $[4 / 17]$ $23.5 \% /[2 / 17] 12 \%)$. Similar to WordID, 35\% (6/17) of students were at or below the $10^{\text {th }}$ percentile prior to remediation. However, following intervention only $12 \%(2 / 17)$ of students were at or below the $10^{\text {th }}$ percentile and no student was below the $5^{\text {th }}$ percentile.

Next, we inspected standard score point changes in single word (WordID), pseudoword (WordAT), and reading comprehension (PassComp). Again, we used Torgesen's (2002) standard score gain of 2 points in word reading and 3-4 points in pseudoword reading as our benchmark. For reading comprehension we used a 1.8 point gain, which was the average gain for the four studies examined by Torgesen. The top section of Table 5 displays the percentage of students whose reading difficulties were stabilized, or improved across pre- to posttest. Percentages of students demonstrating improvements across each of the reading measures were as follows; single word reading, 59\% (10/17) pseudoword reading, 59\% (10/17) and for reading comprehension, 59\% (10/17). This was the evidence for a very balanced improvement across all reading measures.

TABLE 5: Percentage of Participants Showing Standard Score Improvements on Reading Measures Following PREP Booster

\begin{tabular}{|l|c|c|c|}
\hline $\begin{array}{l}\text { Standard score } \\
\text { point gains }\end{array}$ & $\begin{array}{c}\text { SingleWord } \\
\text { Reading }\end{array}$ & $\begin{array}{c}\text { PseudoWord } \\
\text { Reading }\end{array}$ & $\begin{array}{c}\text { Reading } \\
\text { Comprehension }\end{array}$ \\
\hline Stabilized $^{\mathrm{a}}$ & $12 \%(2 / 17)$ & $29 \%(5 / 17)$ & $18 \%(3 / 17)$ \\
Additional 5 point gain $^{\mathrm{b}}$ & $35 \%(6 / 17)$ & $53 \%(9 / 17)$ & $35 \%(6 / 17)$ \\
Additional 10 point gain & $23.5 \%(4 / 17)$ & $6 \%(1 / 17)$ & $18 \%(3 / 17)$ \\
$>10$ point gain & $0 \%(0 / 17)$ & $0 \%(0 / 17)$ & $6 \%(1 / 17)$ \\
Gains per hours of instruction & .18 & .22 & .26 \\
\hline
\end{tabular}

aWordID/PassComp (0-1 pt gain); WordAT (0-2 pt gain)

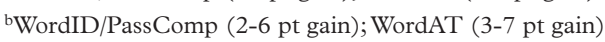

cWordID/PassComp (7-11 pt gain); WordAT (8-12 pt gain)

${ }^{\mathrm{d} W o r d I D / P a s s C o m p ~(>11 p t ~ g a i n) ; ~ W o r d A T ~(>~} 12 \mathrm{pt}$ gain)

\section{STUdy 2: Discussion}

Following additional remediation, statistical analyses revealed that PREP participants evidenced continued improvements in their reading skills. For reading comprehension, significant improvements were found across percentiles for the poorest readers and for ratio of improvements per hours of instruction. 


\section{Conclusions: STudy 1 And Study 2}

We examined short and long-term effects of cognitive (PREP) and phonics (RM) remediation programs in the two studies and conclude that PREP should be considered as an effective remedial program even for chronically poor readers such as the First Nations children if administered for 20-22 hours. The results showed also that, following the PREP booster, significant improvements were evidenced in reading comprehension whereby there were no students performing below the $5^{\text {th }}$ percentile following the booster sessions.

We found that RM participants made superior gains in word decoding. Examining standard score point gains based on hours of instruction we found another encouraging result regarding RM: For word decoding, RM participants improved more than the benchmark established by Torgesen's (2002) meta-analysis, while PREP participants were within the range ascribed by Torgesen. A slight advantage was also evident for RM for single word reading.

\section{Limitations of the Study}

The most obvious limitation for Study 1 is the fact that the remediation was conducted over a short period of time and our control group was actually a «no-risk» group. Logically, children who have long standing reading deficits require a longer period of intervention than we were able to provide. Hence in Study 2, we provided additional sessions, but after a gap of a few months. By that time, the students had been promoted to the next grade. However, in spite of the relatively short duration compared to the 30-80 hours mentioned in Torgesen's (2002) review paper, it is remarkable to observe positive gains in word reading and word decoding in Study 1. This is noticeable when looking at stronger and weaker reader groups; there were substantive improvements.

Thus, it will be important to test the differential effects of direct instruction versus inductive learning programs over an entire school year. In addition, school absenteeism was an ongoing issue throughout the study. While the instructors attempted to conduct make-up sessions, it was not possible to ensure that all children completed the program. To overcome such constraints a 1:1 or 1:2 student/instructor ratio would be optimal.

Finally, we do acknowledge that a control group similar to the treatment group would have been beneficial, for both Study 1 and Study 2. We need a control group without PREP treatment, but of comparable reading deficit. However, we were also dealing with the school's request for treatment for all children. Doing research in real world contexts constantly requires compromises and this was one we were willing to make in order to conduct research in a community with long-term reading failure.

\section{Overall Conclusion}

In conclusion, we consider the central messages of the present study. First, should we choose between a phonics-based and an inductive learning remediation program? On the one hand, the PB program was more explicit in teaching phonological skills and other related skills required in reading. On the other hand, PREP has a relatively holistic approach, integrating global cognitive processes and bridging those to reading skills. 
PREP aims at reduced input from the instructor while encouraging discovery of strategies; the child has ownership of the strategies that he or she discovers. PREP is thus consistent with procedures advocated by Campione and Brown (1987), Chi, Siler, Jeong, Yamauchi, and Hausmann (2001), and Luria's (1981) fundamental approach to learning as a collaborative effort rooted in social-cultural interactions. As Chi et al. (2001) suggested, interactive teaching is effective because students generate reflective comments and construct arguments. These were consistently encouraged in PREP intervention. For example, «How did you figure out how to do it?» «Why did you do it this way?» Rather than providing strategies, the teacher encouraged ongoing reflection, and practice followed by application and evaluation of child-initiated strategies. Comprehension skills improve through those practices; we think improvement in comprehension can be partly attributed to them at the end of the booster sessions. We are admittedly biased towards PREP given the long history of its use in our previous studies. The holistic approach of PREP should enhance reading and language related skills beyond word reading; our on-going research shows improvements not only in word reading skills but also in reading comprehension due to PREP intervention consistent with past research findings, including a recent one (Mohapatra, Das, Stack-Cutler, \& Parrila, in press). Poor comprehenders also experience difficulties on higher level tasks including inference generation after reading a passage, being less aware of when they did not understand what they had read, and using working memory to form mental representations of text (Yuill \& Oakhill, 1991). It is logical, then, to assume that as PREP gives them opportunities to improve these processes (not a concern of RM), it improves their comprehension. If these results are replicated, one could recommend PREP to supplement, if not entirely replace direct instructional programs.

\section{REFERENCES}

Adams, M. J. (1990). Beginning to read: Thinking and learning about print. Cambridge, MA: MIT Press.

Blachman, B. A. (1997). Early intervention and phonological awareness: A cautionary tale. In B. A. Blachman (Ed.), Foundations of reading acquisition: Implications for early intervention (pp. 409-430). Mahwah, NJ: Lawrence Erlbaum Associates.

Blachman, B. A., Schatschneider, C., Fletcher, J. M., Francis, D. J., Clonan, S. M., Shaywitz, B. A., et al. (2004). Effects of intensive reading remediation for second and third graders and a 1-year follow-up. Journal of Educational Psychology, 96, 444-461.

Brailsford, A., Snart, F., \& Das, J. P. (1984). Strategy training and reading comprehension. Journal of Learning Disabilities, 17, 287-290.

Bus, A. G., \& van IJzendoorn, M. H. (1999). Phonological awareness and early reading: A meta-analysis of experimental training studies. Journal of Educational Psychology, 91, 403-414.

Campione, J., \& Brown, A. (1987). Linking dynamic assessment with school achievement. In C. Lidz (Ed.), An international approach to evaluating learning potential (pp. 82-115). New York: Guildford Press.

Chi, M. T., Siler, S. A., Jeong, H., Yamauchi, T., \& Hausmann, R. G. (2001). Learning from human tutoring. Cognitive Science, 25, 471-533

Cohen, J. (1988). Statistical power analysis for the behavioral sciences (Rev. ed.). Hillsdale, NJ: Lawrence Erlbaum Associates.

Das, J. P., Georgiou, G., \& Janzen, T. (2008). Influence of distal and proximal cognitive processes on word reading. Reading Psychology, 29, 1-29. 
Das, J. P., Mishra, R. K., \& Kirby, J. R. (1994). Cognitive patterns of children with dyslexia: A comparison between groups with high and average non-verbal intelligence. Journal of Learning Disabilities, 27, 235242, 253.

Das, J. P., Mishra, R. K., \& Pool, J. E. (1995). An experiment on cognitive remediation of word-reading difficulty. Journal of Learning Disabilities, 28, 66-79.

Das, J. P., Naglieri, J. A., \& Kirby, J. R. (1994). Assessment of cognitive processes: The PASS theory of intelligence. Boston: Allyn \& Bacon.

de Jong, P. F., \& Vrielink, L. O. (2004). Rapid automatic naming: Easy to measure, hard to improve (quickly). Annals of Dyslexia, 54, 65-88.

Dehyle, D. (1992). Constructing failure and maintaining cultural identity: Navajo and Ute school leavers. Journal of American Indian Education, 31(2), 24-47.

Department of Indian and Northern Development (2005). Retrieved September 6, 2005 from http://www.ainc-inac.gc.ca/pr/ info/info34_e.html

Engelmann, S. \& Bruner, E. C. (1995a). Reading Mastery I. Worthington, OH: SRA Division of Macmillan/ McGraw-Hill School Publishing Company.

Engelmann, S. \& Bruner, E. C. (1995b). Reading Mastery II. Worthington, OH: SRA Division of Macmillan/ McGraw-Hill School Publishing Company.

Fawcett, A., Nicolson, R., Moss, H., Nicolson, M., \& Reason, R. (2001). Effectiveness of reading intervention in junior school. Educational Psychology, 21, 299-312.

Foorman, B. R., Francis, D. J., Winikates, D., Mehta, P., Schatchneider, C., \& Fletcher, J. M. (1997). Early intervention for children with reading disabilities. Scientific Studies of Reading, 1, 255-276.

Georgiou, G., Parrila, R., \& Kirby, J. (2006). Rapid automatized naming components and early reading acquisition. Scientific Studies of Reading, 10, 199-220.

Goswami, U., \& Bryant, P. E. (1990). Phonological skills and learning to read. London: Erlbaum.

Janzen, T. M. (2000). Assessment and remediation using the PASS theory with Canadian natives. Unpublished doctoral dissertation, University of Alberta, Edmonton, Canada.

Joseph, L. M., McCachran, M. E., \& Naglieri, J. A. (2003). PASS cognitive processes, phonological processes, and the basic reading performance for a sample of referred primary-grade children. Journal of Research in Reading, 26, 304-314.

Kirby, J. R., Booth, C. A., \& Das, J. P. (1996). Cognitive processes and IQ in reading disability. Journal of Special Education, 29, 442-456.

Kirby, J., Parrila, R., \& Pfeiffer, S. (2003). Naming speed and phonological awareness as predictors of reading development. Journal of Educational Psychology, 95, 453-464.

Lovett, M., Lacerenza, L., \& Borden, S. L. (2000). Putting struggling readers on the PHAST track: A program to integrate phonological and strategy based remedial reading instruction and maximize outcomes. Journal of Learning Disabilities, 33, 458-476.

Luria, A. R. (1981). Language and cognition. New York, NY: John Wiley and Sons.

Manis, F. R., Doi, L. M., \& Bhadha, B. (2000). Naming speed, phonological awareness, and orthographic knowledge in second graders. Journal of Learning Disabilities, 33, 325-333.

Mohapatra, S., Das, J. P., Stack-Cutler, H., \& Parrila, R. K. (in press). Remediating reading comprehension difficulties: A cognitive processing approach. Journal of Research in Reading.

Molina, S., Garrido, M., \& Das, J. P. (1997). Process-based enhancement of reading: An empirical study. Developmental Disabilities Bulletin, 25, 8-76.

Naglieri, J. A., \& Das, J. P. (1997). Cognitive assessment system interpretive handbook. Itasca, IL: Riverside Publishing Company.

Naglieri, J. A., \& Reardon, S. M. (1993). Traditional IQ is irrelevant to learning disabilities-intelligence is not. Journal of Learning Disabilities, 26, 127-133.

Naglieri, J. A., \& Rojahn, J. R. (2004). Validity of the PASS Theory and CAS: Correlations with achievement. Journal of Educational Psychology, 96, 174-181. 
O’Shaughnessy, T., \& Swanson, H. L. (2000). A comparison of two reading interventions for children with reading disabilities. Journal of Learning Disabilities, 33, 257-277.

Papadopoulos, T. C. (2001). Phonological and cognitive correlates of word-reading acquisition under two different instructional approaches. European Journal of Psychology of Education, 26, 549-567.

Papadopoulos, T. C., Charalambous, A., Kanari, A., \& Loizou, M. (2004). Kindergarten cognitive intervention for reading difficulties: The PREP remediation in Greek. European Journal of Psychology of Education, 19, 79-105.

Papadopoulos, T. C., Das, J. P., Parrila, R. K., \& Kirby, J. R. (2003). Children at risk for developing reading difficulties: A remediation study. School Psychology International, 24, 1-27.

Parrila, R. K., Kirby, J. R., \& McQuarrie, L. (2004). Articulation rate, naming speed, verbal short-term memory, and phonological awareness: Longitudinal predictors of early reading development? Scientific Studies in Reading, 8, 3-26.

Parrila, R., Das, J. P., Kendrick, M. E., Papadopoulos, T. C., \& Kirby, J. R. (1999). Efficacy of a cognitive reading remediation program for at-risk children in grade 1. Developmental Disabilities Bulletin, 27, 1-31.

Scarborough, H. S. (1998). Early identification of children at risk for reading disabilities: Phonological awareness and some other promising predictors. In B. Shapiro, P. Accardo, \& A. Capute (Eds.), Specific reading disability: A view of the spectrum (pp. 75-119). Timonium, MD: York Press.

Schneider, W., Ennemoser, M., Roth, E., \& Küspert, P. (1999). Kindergarten prevention of dyslexia: Does training in phonological awareness work for everybody? Journal of Learning Disabilities, 32, 429-436.

Share, D. L., \& Stanovich, K. E. (1995). Cognitive processes in early reading development: Accommodating individual differences into a model of acquisition. Issues in Education, 1, 1-57.

Stanovich, K. E. (1992). Speculations on the causes and consequences of individual differences in early reading acquisition. In P. B. Gough, L. C. Ehri, \& R. Treiman (Eds.), Reading acquisition (pp. 307-342). Hillsdale, NJ: Erlbaum Associates.

Thaler, V., Ebner, E. M., Wimmer, H., \& Landerl, K. (2004). Training reading fluency in dysfluent readers with high reading accuracy: Word specific effects but low transfer to untrained words. Annals of Dyslexia, 54, 89-113.

Torgesen, J. K. (2002). Lessons learned from intervention research in reading: A way to go before we rest. British Journal of Educational Psychology: Monograph Series II: Learning and Teaching Reading, 89-103.

Torgesen, J. K., Wagner, R. K., Rashotte, C. A., Alexander, A. W., \& Conway, T. (1997). Preventive and remedial interventions for children with severe reading disabilities. Journal of Learning Disabilities, 8, 51-61.

Torgesen, J. K., Wagner, R. K., Rashotte, C. A., Burgess, S., \& Hecht, S. (1997). Contributions of phonological awareness and rapid automatized naming ability to growth of word-reading skills in second- to fifthgrade children. Scientific Studies of Reading, 1, 161-185.

Wagner, R., Torgesen, J., Laughon, P., Simmons, K., \& Rashotte, C. (1993). Development of young readers' phonological processing abilities. Journal of Educational Psychology, 85, 83-103.

Wagner, R., Torgesen, J., \& Rashotte, C., A. (1999). CTOPP: Comprehensive test of phonological processing. Austin, TX: PRO-ED.

Wolf, M., \& Bowers, P. G. (1999). The double-deficit hypothesis for the developmental dyslexias. Journal of Educational Psychology, 91, 415-438.

Wolf, M., Bowers, P. G., \& Biddle, K. (2000). Naming-speed processes, timing, and reading: A conceptual review. Journal of Learning Disabilities, 33, 387-407.

Wolf, M., Miller, L., \& Donnelly, K. (2000). Retrieval, automaticity, vocabulary elaboration, orthography (RAVE-O): A comprehensive, fluency-based reading intervention program. Journal of Learning Disabilities, 33, 375-386.

Woodcock, R. W., McGrew, K. S., \& Mather, N. (2001). Woodcock-Johnson Tests of

Achievement (WJ III). Itasca, IL: Riverside Publishing.

Yuill, N., \& Oakhill, J. (1991). Children's problems in text comprehension: An experimental investigation. Cambridge, UK: Cambridge University Press. 
J.P. Das. Developmental Disabilities Centre. 6123 Education. University of Alberta. Edmonton, Canada.T5G 2E5.J.P.Das@ualberta.ca 